\title{
O DOENTE CONFUSO E A AÇÃO DE ENFERMAGEM, EM MEIO HOSPITALAR*
}

Paulo Alexandre Oliveira Marques ${ }^{1}$, Paulino Sousa ${ }^{2}$, Abel Silva $^{3}$

RESUMO: Este resumo deriva de tese centrada no domínio do doente com 'confusão'. Emergiu de um processo de investigação-ação desenvolvido em uma unidade de doentes agudos do foro médico, entre 2007 a 2010, no Hospital Pedro Hispano -Portugal, onde se concretizou um percurso de mudança. Caracterizou-se como pesquisa exploratória, descritiva e correlacional cujos objetivos foram: identificar um modelo de cuidados que suportasse a ação e a gestão do doente confuso, pelos enfermeiros; identificar a utilidade clínica do foco 'confusão' para os enfermeiros; identificar as condições do doente que interferiam na conceção de cuidados de enfermagem ao doente confuso; identificar as intervenções de enfermagem que se mostravam mais adequadas para lidar com o doente confuso; e identificar os fatores que interferiram com o processo de mudança na estrutura e nos conteúdos que suportam e consubstanciam os cuidados a esses doentes. Os dados foram obtidos por meio de entrevistas a 19 enfermeiros, análise de documentação e observação participante, e submetidos à análise iterativa. Esta investigação teve por base a adoção de um paradigma construtivista para gerar uma Teoria Fundamentada nos Dados explicativa da mudança na assistência ao doente confuso. O refinamento diagnóstico, com a introdução da Escala de Confusão Neecham; a consideração de condições como o status funcional e a resposta comportamental, que influem na identificação de problemas co-relacionados, como por exemplo, risco de queda; e a implementação de intervenções, como a Orientação para a Realidade e a Terapia de Validação, alicerçadas numa estrutura de apoio à decisão clínica dos enfermeiros, tradutoras de mudanças nas práticas de cuidados, teve impacto positivo sobre os doentes: a) melhoria objetiva na qualidade do diagnóstico; b) consciencialização da natureza das intervenções mobilizáveis para lidar com a 'confusão' do doente, muito para além do que existia; c) quantidade e qualidade dos itens de informação (representação na documentação) muito superior; d) definição de um modelo de abordagem a diferentes tipos de doentes com 'confusão'; e em termos de validação, e) as intervenções que contribuíram para ganhos em saúde; f) capacidade do modelo para interferir positivamente na prevenção da queda; e g) opinião positiva dos enfermeiros relativamente ao sistema. PALAVRAS-CHAVE: Confusão; Técnicas de apoio para a decisão; Enfermagem.

*Resumo da tese de doutoramento em Enfermagem apresentada ao Instituto de Ciências da Saúde da Universidade Católica Portuguesa, Portugal.

${ }^{1}$ Enfermeiro. Doutor em Enfermagem. Professor do Curso de Pós-Graduação em Enfermagem Médico-Cirúrgica da ESEP. Pesquisador da unidade de investigação da ESEP.

${ }^{2}$ Enfermeiro. Doutor em Enfermagem. Diretor do Centro de Iinvestigação e Desenvolvimento de Sistemas de Informação da ESEP. ${ }^{3}$ Enfermeiro. Doutor em Enfermagem. Presidente do Conselho Técnico-Científico da ESEP. 